\title{
A hemodialysis patient with bone disease after pregnancy: a case report
}

\author{
Hannelore Sprenger-Mähr ${ }^{1}$, Emanuel Zitt ${ }^{1}$, Andreas Kronbichler ${ }^{2}$, Manfred Cejna ${ }^{3}$ and Karl Lhotta ${ }^{1 *}$ (D
}

\begin{abstract}
Background: Pregnancy is rare in women on hemodialysis. Recommendations for the treatment of secondary hyperparathyroidism (sHPT) and preservation of bone health in pregnant dialysis patients are lacking.

Case presentation: We present the case of a young woman with end-stage kidney disease (ESKD) due to lupus nephritis, who developed multiple brown tumors while on hemodialysis during her second pregnancy. During her first pregnancy sHPT was well controlled and no skeletal complications occurred. Before the second pregnancy she developed severe sHPT. During pregnancy, dialysis time was increased to $24 \mathrm{~h}$ per week, the patient was given oral calcitriol, and the dialysate calcium concentration was set at $1.5 \mathrm{mmol} / \mathrm{l}$. In week 20 the patient complained about bone pain in her left hip. Magnetic resonance imaging revealed a cystic lesion compatible with a brown tumor. The baby was delivered in the 36th week by cesarean section. Further assessment identified multiple brown tumors of her skeleton, including the acetabulum, tibia, ribs, skull, thoracic spine and thumb. She required multiple orthopedic surgeries. Three months after pregnancy, etelcalcetide was started, which brought about a gradual improvement in her SHPT.
\end{abstract}

Conclusions: This case demonstrates that the combination of pregnancy and severe sHPT in dialysis patients can have deleterious consequences for bone health.

Keywords: Hemodialysis, Secondary hyperparathyroidism, Osteitis fibrosa cystica, Pregnancy, Etelcalcetide

\section{Background}

Practically all dialysis patients have chronic kidney disease-associated mineral and bone disorder (CKD$\mathrm{MBD}$ ), with secondary hyperparathyroidism (sHPT) being most frequent. The most severe form of hyperparathyroid bone disease is osteitis fibrosa cystica (OFC) caused by massive bone resorption mediated by parathyroid hormone (PTH). The clinical presentation is characterized by bone pain and swelling, skeletal deformities and fractures. Imaging studies show osteolytic bone lesions [1]. Histologically, multinucleated osteoclasts (giant cells) with tunneling bone resorption, peritrabecular fibrosis and woven bone are pathognomonic findings. Hemosiderin deposition causes the macroscopic appearance of a brown tumor (BT). Current treatment options for sHPT such as phosphate binders, calcitriol and its analogs, calcimimetics, and finally parathyroidectomy, have made OFC a

\footnotetext{
* Correspondence: karl.lhotta@lkhf.at

${ }^{1}$ Department of Internal Medicine III, Academic Teaching Hospital Feldkirch, Carinagasse 47, Feldkirch, Austria

Full list of author information is available at the end of the article
}

rare finding in dialysis patients [2, 3]. OFC occasionally develops in patients with primary hyperparathyroidism (pHPT). Pregnant women with pHPT seem to be predisposed to OFC, as illustrated by numerous case reports, suggesting that in pregnancy bone is particularly vulnerable to the effect of PTH [4-7]. The combination of severe sHPT in a dialysis patient and pregnancy may therefore be the worst-case scenario for bone health. As pregnancy is still very rare in women of childbearing age on dialysis, data on bone disease in that clinical situation are practically absent and guidance for sHPT treatment and the preservation of bone health in pregnant dialysis patients is lacking. We here report the case of a young woman on hemodialysis, who had two successful pregnancies. After the second one, which she entered with severe sHPT, she developed devastating and refractory OFC.

\section{Case report}

The 26-year-old Caucasian woman had developed endstage kidney disease (ESKD) at the age of 21 due to lupus nephritis. She was treated with conventional 
maintenance hemodialysis therapy three times a week. At age 22 she became pregnant for the first time. Pregnancy was first recognized at 23 weeks of gestation. The dialysis schedule was intensified to $24 \mathrm{~h}$ per week. The patient was treated with sevelamer. She received no vitamin $\mathrm{D}$ or calcium and the dialysis bath calcium concentration was kept at $1.25 \mathrm{mmol} / \mathrm{l}$. During pregnancy CKD-MBD was well controlled with calcium and phosphate levels in the normal range and PTH levels around $150 \mathrm{pg} / \mathrm{ml}$. The baby was delivered in week 32 by cesarean section. The premature child was small for gestational age with a birth weight of $1735 \mathrm{~g}$, and a length of $43 \mathrm{~cm}$. Apgar score was $7 / 8 / 9$. The mother breastfed the newborn for only a few weeks.

During the following three years the patient developed severe sHPT with gradually increasing PTH levels to around $1500 \mathrm{pg} / \mathrm{ml}$, primarily because she refused to take any oral medication such as phosphate binders, calcitriol or cinacalcet.

At age 25 she became pregnant again. Her dialysis schedule was increased to $24 \mathrm{~h}$ per week $(6 \times 4 \mathrm{~h})$, according to the current recommendations [8]. Dry weight was adjusted weekly, erythropoetin and iron supplementation were adapted as required. Oral calcitriol $0.25 \mu \mathrm{g}$ after each dialysis session and cholecalciferol $6000 \mathrm{IU}$ per week were administered and the dialysate calcium concentration was increased to $1.5 \mathrm{mmol} / \mathrm{l}$. The patient was normophosphatemic, serum calcium was at the lower limits of normal and PTH decreased from about $1600 \mathrm{pg} / \mathrm{ml}$ to around 500 to $800 \mathrm{pg} / \mathrm{ml}$ (time-course of calcium and PTH is shown in Figs. 1 and 2). Table 1 depicts levels of serum phosphate, alkaline phosphatase and $25 \mathrm{OH}-$ vitamin D3 before, during and after her second pregnancy.

At 20 weeks of gestation the patient began to complain about pain in her right hip. Magnetic imaging revealed a cystic lesion in the right acetabulum, femoral neck and trochanter majus, highly suggestive of a BT.

After 36 weeks of gestation the patient gave birth to a female baby by cesarean section. Apgar score was 8/10/ 10, birth weight was $2755 \mathrm{~g}$, and body length $47 \mathrm{~cm}$. Except for a complete atrioventricular septum defect, which had already been diagnosed prenatally, the baby was healthy. The patient breastfed the neonate for five weeks.

After pregnancy, hemodialysis frequency was reduced to a conventional schedule of four hours three times weekly. PTH levels started to increase rapidly again, reaching up to $2000 \mathrm{pg} / \mathrm{ml}$ (Fig. 2). Treatment with cinacalcet with rapid dose increase from 30 to $90 \mathrm{mg}$ was started, and calcitriol was continued at $0.5 \mu \mathrm{g}$. Both cinacalcet and calcitriol were given three times per week after the dialysis session, because the patient refused to take these medications on dialysis-free days. Further computed tomography, magnetic resonance and $\mathrm{x}$-ray imaging identified multiple additional BTs of her skeleton, including the right acetabulum, the right trochanter majus, os pubis (Fig. 3a), the right tibia (Fig. 3b), several ribs, the skull and the left thumb (Fig. 3c). The patient had to be partially immobilized because of the high fracture risk. The BT in the right acetabulum and right tibia were enucleated, and the cavities were filled with autologous and homologous bone graft and an osteosynthesis of the tibia had to be performed for stabilization. Histopathology of the enucleated material confirmed the diagnosis of BTs, showing cell-rich tumor tissue with osteoclastic giant cells, multiple sideromacrophages and hemosiderin deposition (Fig. 4).

Despite treatment with cinacalcet, PTH concentration remained at around $1500 \mathrm{pg} / \mathrm{ml}$. At that time, etelcalcetide was approved by the European Medicines Agency.

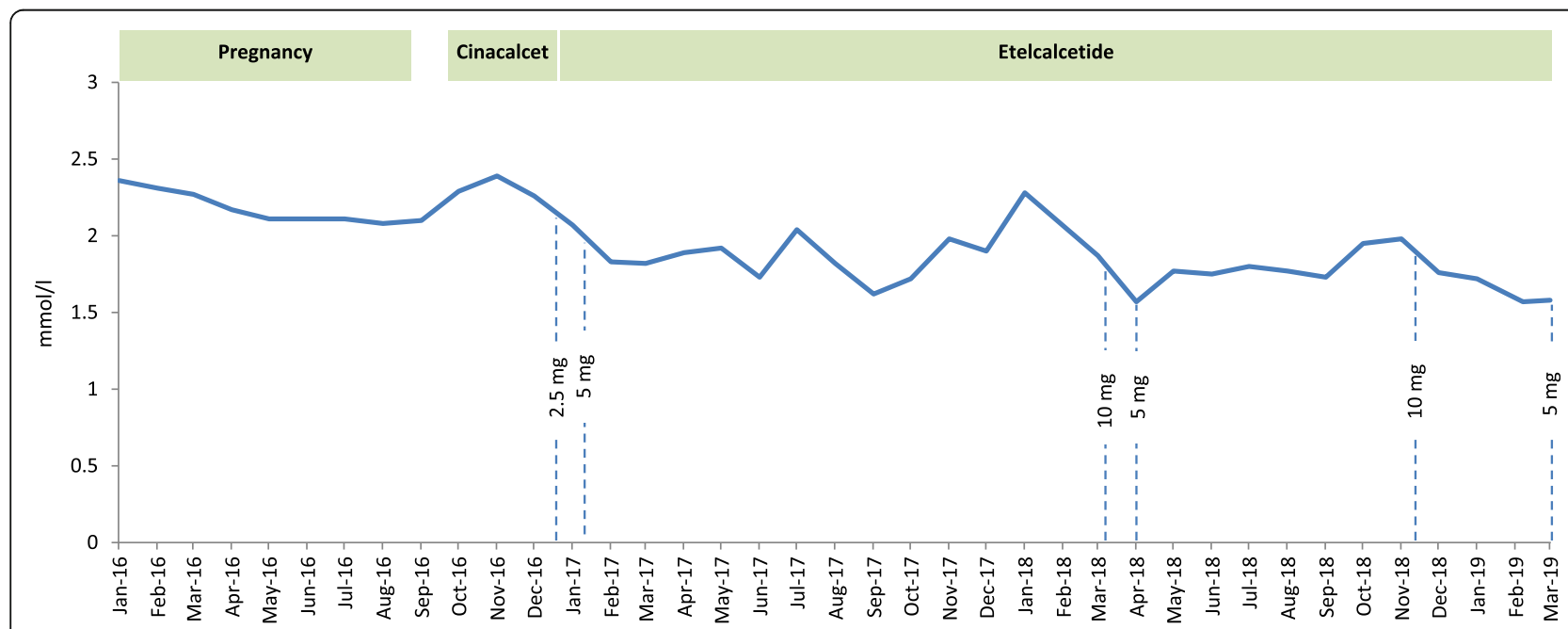

Fig. 1 Monthly serum calcium levels starting with the seond pregnancy pregnancy. Calcium was normal during pregnancy. Under treatment with etelcalcetide mild hypocalcemia was present 


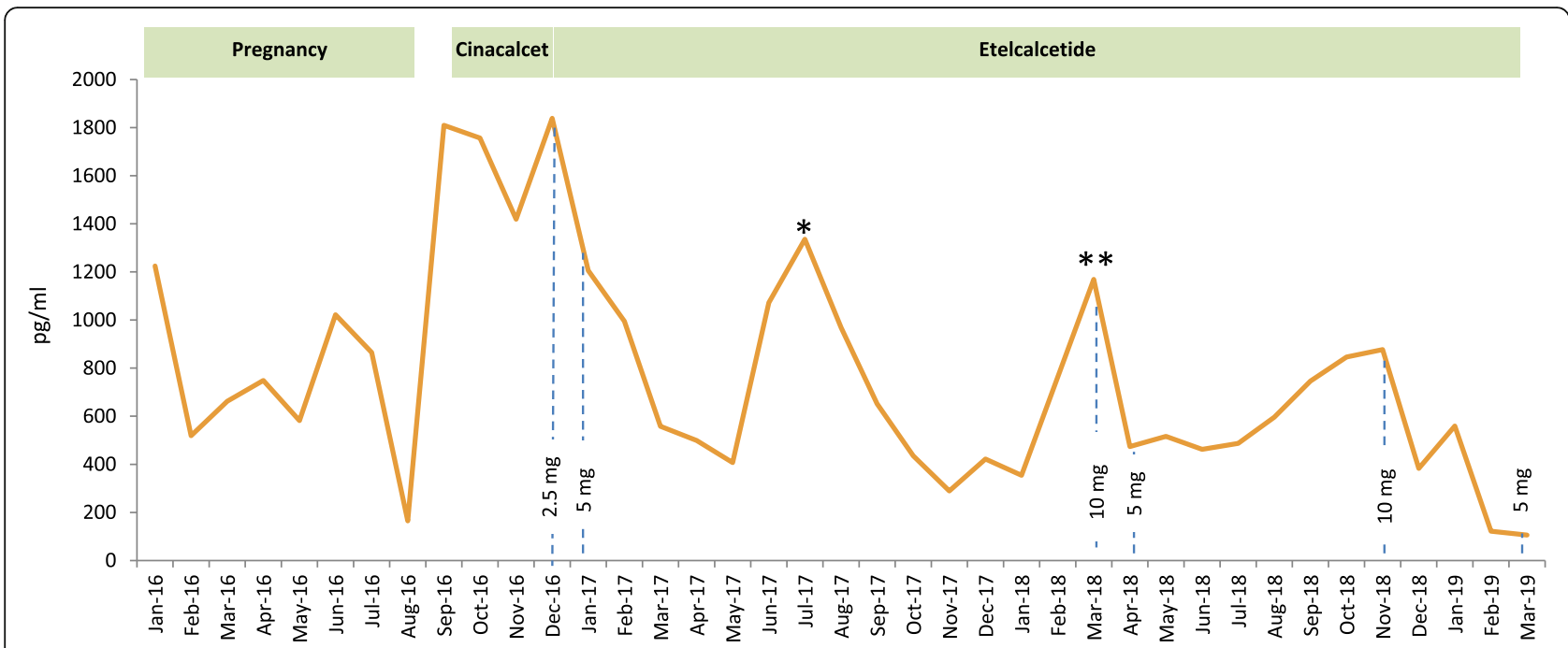

Fig. 2 Monthly PTH levels starting with the second of pregnancy. PTH declined during pregnancy and especially with etelcalcetide. Two rebounds of PTH were caused by a *two-week and a **three-week treatment period in another unit, where etelcalcetide was not available. PTH was measured with a third generation 1-84 intact PTH assay (Elecsys PTH (1-84) assay, Roche)

Three months after delivery treatment with etelcalcetide was initiated. The initial dose of $2.5 \mathrm{mg}$ after hemodialysis had to be gradually increased to $10 \mathrm{mg}$ per dialysis session. Although PTH decreased to around $500 \mathrm{pg} / \mathrm{ml}$ and further on to $200 \mathrm{pg} / \mathrm{ml}$ when undergoing treatment with etelcalcetide (Fig. 2), OFC lesions did not show any sign of regression. Second enucleations of the $\mathrm{BT}$ in the right acetabulum and in the right tibia became necessary eight and 12 months after starting with etelcalcetide, because the bone grafts had been absorbed. In spite of sHPT being well-controlled with etelcalcetide, calcium and calcitriol supplementation, a new BT developed in the thoracic spine two years after starting etelcalcetide. A costotransversectomy on the right side of the fifth thoracic vertebral body, filling of the cavity with homologous bone graft and spondylodesis TH 4 to TH 6 was performed. Table 2 summarizes all surgical procedures performed during the course of the disease. After all these interventions the patient was fully mobile and without pain. Bone mineral density assessed by dualenergy $\mathrm{x}$-ray absorptiometry in the second year after pregnancy revealed low bone mass (osteopenia) both in the lumbar spine $\left(0.970 \mathrm{~g} / \mathrm{cm}^{2}, \mathrm{~T}\right.$-score -1.8$)$ and femoral necks $\left(0.760 \mathrm{~g} / \mathrm{cm}^{2}\right.$, T-score -2.0$)$.

\section{Discussion and conclusions}

This case illustrates that uncontrolled sHPT during pregnancy in a dialysis patient can have deleterious effects for the maternal skeleton.

Pregnancy, particularly multiparity, is still rare in dialysis patients. A systematic review demonstrated an increasing number of reported pregnancies from 90 cases in the period from 2000 to 2008 to 574 pregnancies in 543 women from 2000 to 2014 [9]. Increased dialysis dose goes along with higher fertility and intensified dialysis schedules, especially daily hemodialysis, quotidian long-hour dialysis or nocturnal hemodialysis, result in better maternal and fetal outcomes [10, 11].

OFC is a rare manifestation of severe pHPT and sHPT, especially in developed countries. Osteoclastic bone resorption with destruction of trabeculae is accompanied by cellular repair mechanisms that result in the accumulation of fibrous stroma and connective tissue cells along with multinucleated giant cells. The name "brown tumor" derives from the color, which is caused by hypervascularity, hemorrhage and deposits of hemosiderin. The lesions are localized in areas of intense bone resorption, preferentially in the facial skeleton but also in the clavicle, ribs and pelvic bones [4]. On imaging,

Table 1 Other relevant laboratory parameters before, during and after the second pregnancy

\begin{tabular}{llllll}
\hline parameter (normal range) & $\begin{array}{l}\text { 3 month before } \\
\text { second pregnancy }\end{array}$ & 1. trimenon & 2. trimenon & 3. trimenon & $\begin{array}{c}3 \text { months after } \\
\text { pregnancy }\end{array}$ \\
\hline phosphate $(0.81-1.45 \mathrm{mmol} / \mathrm{l})$ & 2.33 & 1,08 & 0,94 & 1,24 & 1.71 \\
alkaline phosphatase $(35-105 \mathrm{U} / \mathrm{l})$ & 306 & 327 & 261 & 366 & 235 \\
$25 \mathrm{OH}$-vitamin D3 $(20-100 \mu \mathrm{g} / \mathrm{l})$ & 14 & 13 & 11 & 19 & 11 \\
\hline
\end{tabular}



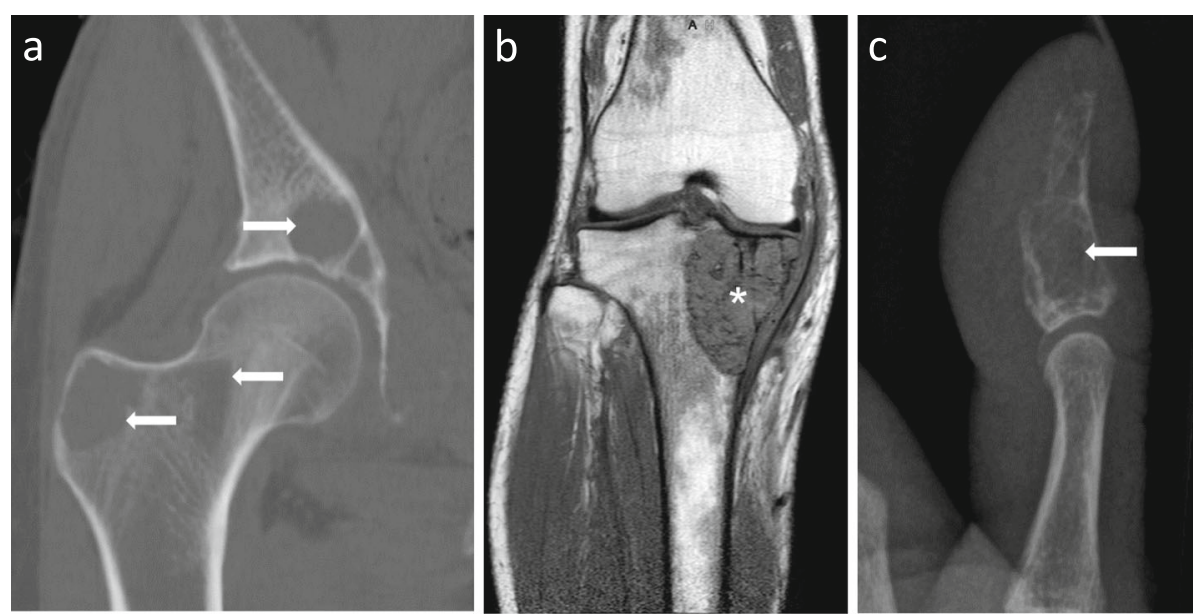

Fig. 3 Imaging studies of selected osteolytic lesions. a. CT scan of the right hip. Osteolytic lesions are present in the acetabulum, femoral neck and trochanter majus (arrows). b. MRI scan showing a large brown tumor in the head of the right tibia $(*)$. c. x-ray of the left thumb reveals osteolytic destruction of the end phalanx (arrow)

they appear as lytic lesions with regular borders and thinned cortical bone, not accompanied by periosteal reaction or inflammation.

In general, BTs are three times more common in women than in men, possibly related to the large amounts of calcium and vitamin $\mathrm{D}$ required during pregnancy and lactation [4].

In pregnancy adaptive mechanisms are needed to cope with the calcium requirements of the developing fetus. The human fetus accretes about $30 \mathrm{~g}$ of calcium by term, mostly in the third trimester [12]. To meet this increased

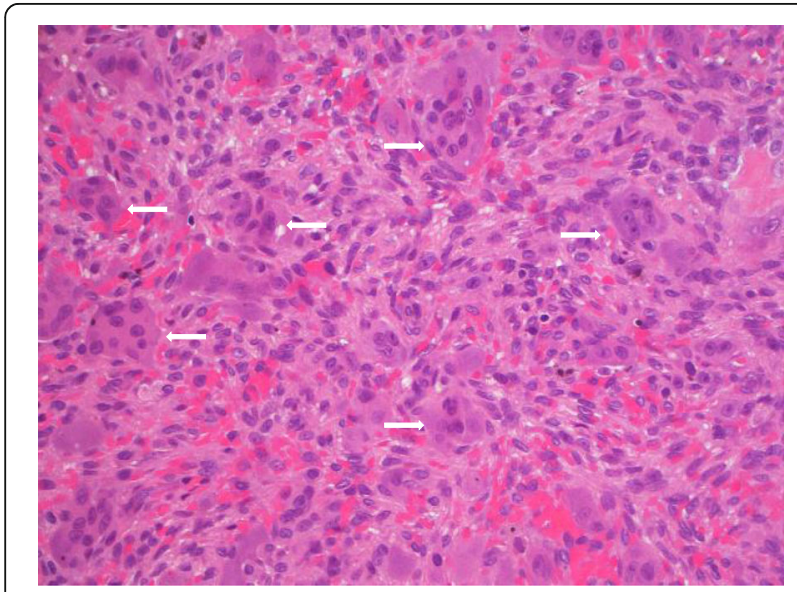

Fig. 4 Histopathology of the brown tumor removed from the right tibia. Hematoxylin-eosin staining (400x magnification). Proliferation of mesenchymal cells with oval nuclei and eosinophilic cytoplasm. Scattered throughout the stroma are numerous osteoclast-like multinucleated giant cells containing varying numbers of vesicular nuclei (arrows) demand maternal intestinal calcium absorption more than doubles beginning in the 12th week of pregnancy, driven in part by an increase in serum calcitriol [13]. PTH is suppressed and therefore not the cause of increased calcitriol levels. Evidence from animal models suggests that prolactin or placental lactogen, and also PTH-related peptide (PTHrP) may stimulate the renal $1 \alpha$-hydroxylase to produce calcitriol [12]. Although the placenta also expresses the key enzyme $1 \alpha$-hydroxylase, it seems that the maternal kidneys account for most of the circulating calcitriol during pregnancy, as illustrated by an anephric woman on hemodialysis who had low calcitriol before and during her pregnancy [12].

During lactation, maternal calcium and bone metabolism must adapt to the extra demand for calcium (300-400 mg/days). The major source providing calcium during breastfeeding is bone [14]. Maternal bone mass declines during lactation by about $10 \%$ over the first six months, the losses being greatest in

Table 2 Surgical procedures related to brown tumors performed during the course of the disease

\begin{tabular}{ll}
\hline $\begin{array}{l}\text { Time after } \\
\text { delivery }\end{array}$ & Procedure \\
\hline 3 months & $\begin{array}{l}\text { enucleation of BT in the right tibia and acetabulum } \\
\text { bone graft filling osteosynthesis }\end{array}$ \\
12 months & $\begin{array}{l}\text { enucleation of BT right acetabulum bone graft filling } \\
\text { enucleation of relapsing BT right tibia and acetabulum } \\
\text { bone graft filling osteosynthesis }\end{array}$ \\
16 months & $\begin{array}{l}\text { enucleation of BT in the left thumb } \\
\text { costotransversectomy thoracic vertebra } 5 \text { osteosynthesis } \\
28 \text { months }\end{array}$ \\
\hline
\end{tabular}


the trabecular skeleton [14]. The lactating breast secretes PTHrP into the systemic circulation and milk. PTHrP mobilizes skeletal calcium stores. Concomitant estrogen deficiency secondary to hypogonadotropic hypogonadism may increase bone loss [4]. Randomized clinical trials and observational studies have found that higher calcium supplementation does not reduce lactational bone density decline [15]. In the postweaning phase the skeleton is restored to its previous strength and mineral content [13].

In a pregnant dialysis patient the kidneys obviously cannot increase calcitriol synthesis. Therefore, if calcitriol and calcium are not supplemented, calcium will probably be mobilized from maternal bone. This may be aggravated by preexisting uncontrolled SHPT. In pregnancy, bone is probably particularly vulnerable to the effects of PTH, as exemplified by cases of OFC in pregnant women with pHPT. In addition, the physiologic repair mechanisms of bone in the postweaning phase may not be as effective in an ESKD patient with sHPT. Therefore, our patient may have entered the second pregnancy with an already pre-damaged and vulnerable skeleton.

What implications can be derived from normal physiology during pregnancy and from the bone and mineral derangements in CKD-MBD for the management of a pregnant dialysis patient?

First of all, pregnancy in a dialysis patient needs to be carefully planned with the medical team, not only considering blood pressure, volume or anemia management, but also avoidance or therapy of severe sHPT before entering pregnancy. On both occasions our patient did not inform the medical team about her plan to become pregnant. Pregnancy in a patient with uncontrolled sHPT should not be pursued. The first pregnancy with well controlled sHPT did not cause obvious or clinically significant damage to the maternal skeleton, whereas during the second pregnancy severe sHPT led to generalized OFC.

Second, the special fetal demands for calcium need consideration. The World Health Organization (WHO) recommends daily supplementation of 1.5 to $2 \mathrm{~g}$ of calcium for pregnant women after the 20th week of pregnancy, especially in those at risk for preeclampsia and in regions with low dietary calcium intake [16]. Dialysis patients are at risk for preeclampsia, and their calcium intake from milk products is usually low, because the intake of dairy products is discouraged due to their phosphate content. Therefore, oral calcium supplementation should be considered in a pregnant dialysis patient.

The WHO guidelines for antenatal care advise against routine vitamin D supplementation in pregnancy [17]. In a dialysis patient in whom renal calcitriol synthesis is absent, calcitriol supplementation - and not native vitamin
D supplementation - is probably necessary to facilitate intestinal calcium absorption.

Another means of calcium supplementation in a dialysis patient is to increase the calcium dialysate concentration. Whereas a four hour bicarbonate dialysis with a dialysate calcium of $1.25 \mathrm{mmol} / \mathrm{l}$ results in a neutral calcium balance, increasing the dialysate calcium to 1.5 $\mathrm{mmol} / \mathrm{l}$ provides a positive calcium balance of around $300 \mathrm{mg}$ per session [18]. Whether this amount is sufficient to cover the needs of pregnancy and lactation or whether additional oral supplementation is necessary is unknown. In any case, our patient refused to take oral calcium supplements and increasing calcium in the dialysate bath seemed a plausible alternative.

All these measures, namely intensive dialysis with normalization of serum phosphate levels, calcium and calcitriol supplementation or increasing the dialysis calcium bath, will lead to a reduction in PTH levels, as observed in our patient's second pregnancy.

Cinacalcet and etelcalcetide are calcimimetic agents, which effectively reduce $\mathrm{PTH}$, calcium and phosphorous in dialysis patients [19-21]. With regard to bone turnover and histology, cinacalcet has been shown to decrease histomorphometric markers of bone turnover after six to twelve months of treatment in dialysis patients with biopsy-proven high bone turnover [3]. The package insert for cinacalcet states that cinacalcet should be used during pregnancy only if the benefits outweigh potential harms. Experimental animal studies showed cinacalcet to have no teratogenicity. Only a few case reports describe treatment with cinacalcet during pregnancy, mainly in $\mathrm{pHPT}$ patients to control hypercalcemia, and only for a few weeks during the third trimester $[5,22]$.

CKD-MBD guidelines suggest parathyroidectomy for those patients with severe hyperparathyroidism who fail to respond to pharmacological therapy [23]. Parathyroidectomy during pregnancy has to our knowledge been performed only in pHPT, but not in sHPT [24]. The current recommendation is to perform parathyroidectomy during the second trimester of pregnancy due to incomplete organogenesis in the first trimester and the risk of preterm labor in the third trimester [25]. During pregnancy PTH levels were not in the range above 800 $\mathrm{pg} / \mathrm{ml}$, where surgery is recommended and serum calcium and phosphorus were normal. For this reason, we did not consider parathyroidectomy during the second pregnancy. In the postpartal period with normalization of the dialysis schedule PTH increased rapidly despite cinacalcet (Fig. 2), and parathyroidectomy was strongly considered. We were, however, reluctant to take this step because of the fear of consequent adynamic bone disease precluding the healing of osteolytic lesions, and severe and sustaining hypocalcemia in a patient with known poor adherence in the long term. 
Etelcalcetide is a novel second-generation calcimimetic given intravenously after each hemodialysis session [20]. When this new drug became available, we quickly administered it in our patient. Indeed, our patient was the first to be treated with this new secondgeneration calcimimetic in Europe outside clinical trials. Serum PTH levels declined with increasing doses, but rose episodically whenever the patient was treated for a short period of time in other dialysis units where etelcalcetide was not available at that time. When pharmacological treatment of sHPT to cure OFC is pursued, the precise target level of PTH, which ensures optimal bone turnover for healing, is currently unknown. During the first two years on etelcalcetide PTH levels undulated around $500 \mathrm{pg} / \mathrm{ml}$. As shown in our patient, this level of PTH is obviously too high to allow regression of BTs. Therefore, we targeted a lower level between 100 and $200 \mathrm{pg} / \mathrm{ml}$. Whether this PTH range allows regression of the lesions remains to be seen.

Looking at this case in retrospect, would there have been opportunities to improve patient management and outcome? Using a dialysate calcium concentration of 1.5 $\mathrm{mmol} / \mathrm{l}$ in the period between the two pregnancies might have counteracted the development of severe sHPT. Secondly, parathyroidectomy before the second pregnancy would have been an option bearing in mind the possibility of postsurgical hypoparathyroidism and the development of adynamic bone disease in a young patient (potentially aggravated by her non-adherence). Thirdly, increasing the dose of calcitriol and oral calcium supplementation during pregnancy avoiding overt hypercalcemia may have been considered. Finally, a more liberal up-titration of etelcalcetide to reduce PTH accepting some degree of hypocalcemia could have been helpful.

Should breastfeeding be recommend in a dialysis patient? We are aware of only one case report on this topic [26]. Breast milk composition varies between pre- and post-dialysis samples, and post-dialysis milk is preferable for breastfeeding [26]. Under normal physiologic conditions breastfeeding puts greater stress on the skeleton than does pregnancy itself. Therefore, we suggest that in a patient with SHPT and bone disease breastfeeding should be discouraged to prevent further aggravation of bone resorption.

This case highlights the clinical problems that may arise when a dialysis patient enters pregnancy with severe sHPT. The combined effects of sHPT and pregnancy can cause $\mathrm{OFC}$, requiring multiple surgical interventions. Clinical experience with usual therapeutic interventions to control PTH such as calcimimetic drugs or parathyroidectomy is practically absent. Therefore a woman on hemodialyis should be advised to get pregnant only after $\mathrm{PTH}$ and mineral metabolism are well controlled.

\section{Abbreviations}

BT : Brown tumor; CKD-MBD: Chronic kidney disease-associated mineral and bone disorder; ESKD: End-stage kidney disease; OFC: Osteitis fibrosa cystica; PHPT : Primary hyperparathyroidism; PTH : Parathyroid hormone; PTHrP : PTH-related peptide; SHPT: Secondary hyperparathyroidism; WHO : World Health Organization

\section{Acknowledgements}

The authors thank Amgen Austria for providing etelcalcetide for immediate treatment of our patient.

\section{Authors' contributions}

$H S M, E Z, A K$ and $K L$ are reponsible for the clinical management of the patient, MC for the interpretation of imaging studies. All authors have read and approved the manuscript.

Authors' information

None.

Funding

None.

Availability of data and materials

Data sharing is not applicable.

Ethics approval and consent to participate Not applicable.

\section{Consent for publication}

Written informed consent was optained from the patient for publication of the case report including images.

\section{Competing interests}

The authors declare no competing interests.

\section{Author details}

'Department of Internal Medicine III, Academic Teaching Hospital Feldkirch, Carinagasse 47, Feldkirch, Austria. ${ }^{2}$ Department of Internal Medicine IV, Medical University of Innsbruck, Innsbruck, Austria. Institute for Diagnostic and Interventional Radiology, Academic Teaching Hospital Feldkirch, Feldkirch, Austria.

Received: 1 August 2019 Accepted: 28 October 2019

Published online: 21 November 2019

References

1. Bandeira F, Cassibba S. Hyperparathyroidism and bone health. Curr Rheumatol Rep. 2015;17(7):48.

2. Malluche HH, Mawad HW, Monier-Faugere MC. Renal osteodystrophy in the first decade of the new millennium: analysis of 630 bone biopsies in black and white patients. J Bone Miner Res. 2011;26(6):1368-76.

3. Behets GJ, Spasovski G, Sterling LR, Goodman WG, Spiegel DM, De Broe ME, D'Haese PC. Bone histomorphometry before and after long-term treatment with cinacalcet in dialysis patients with secondary hyperparathyroidism. Kidney Int. 2015:87(4):846-56.

4. Casteras A, Darder L, Zafon C, Hueto JA, Alberola M, Caubet E, Mesa J. Brown tumor of the jaw after pregnancy and lactation in a MEN1 patient. Endocrinol Diabetes Metab Case Rep. 2016;2016.

5. Gonzalo Garcia I, Robles Fradejas M, Martin Macias MLA, Biain Ciganda A, Bustinza Beaskoetxea Z, Ruiz Perez E, Fernandez Matia G, Martinez Guisasola J. Primary hyperparathyroidism in pregnancy treated with cinacalcet: a case report. J Obstet Gynaecol. 2018;38(1):132-4.

6. Lehnerdt $G$, Metz KA, Kruger C, Dost P. A bone-destroying tumor of the maxilla. Reparative giant cell granuloma or brown tumor? HNO. 2003:51(3):239-44.

7. Zou H, Song L, Jia M, Wang $L$, Sun Y. Brown tumor of multiple facial bones associated with primary hyperparathyroidism: a clinical case report. Medicine (Baltimore). 2018;97(33):e11877. 
8. Cabiddu G, Castellino S, Gernone G, Santoro D, Giacchino F, Credendino O, Daidone G, Gregorini G, Moroni G, Attini R, et al. Best practices on pregnancy on dialysis: the Italian study group on kidney and pregnancy. J Nephrol. 2015;28(3):279-88.

9. Piccoli GB, Minelli F, Versino E, Cabiddu G, Attini R, Vigotti FN, Rolfo A, Giuffrida D, Colombi N, Pani A, et al. Pregnancy in dialysis patients in the new millennium: a systematic review and meta-regression analysis correlating dialysis schedules and pregnancy outcomes. Nephrol Dial Transplant. 2016;31(11):1915-34.

10. Hladunewich MA, Hou S, Odutayo A, Cornelis T, Pierratos A, Goldstein M, Tennankore K, Keunen J, Hui D, Chan CT. Intensive hemodialysis associates with improved pregnancy outcomes: a Canadian and United States cohort comparison. J Am Soc Nephrol. 2014;25(5):1103-9.

11. Barua M, Hladunewich M, Keunen J, Pierratos A, McFarlane P, Sood M, Chan CT. Successful pregnancies on nocturnal home hemodialysis. Clin J Am Soc Nephrol. 2008;3(2):392-6.

12. Kovacs CS. Calcium and bone metabolism disorders during pregnancy and lactation. Endocrinol Metab Clin N Am. 2011;40(4):795-826.

13. Kirby BJ, Ma Y, Martin HM, Buckle Favaro KL, Karaplis AC, Kovacs CS. Upregulation of calcitriol during pregnancy and skeletal recovery after lactation do not require parathyroid hormone. J Bone Miner Res. 2013;28(9): 1987-2000.

14. Wysolmerski JJ. Interactions between breast, bone, and brain regulate mineral and skeletal metabolism during lactation. Ann N Y Acad Sci. 2010; 1192:161-9.

15. Kalkwarf HJ, Specker BL, Bianchi DC, Ranz J, Ho M. The effect of calcium supplementation on bone density during lactation and after weaning. $\mathrm{N}$ Engl J Med. 1997;337(8):523-8.

16. . In: Guideline: Calcium Supplementation in Pregnant Women. edn. Geneva; 2013.

17. Roth DE, Leung M, Mesfin E, Qamar H, Watterworth J, Papp E. Vitamin D supplementation during pregnancy: state of the evidence from a systematic review of randomised trials. BMJ. 2017;359:55237.

18. Basile C, Libutti P, Di Turo AL, Vernaglione L, Casucci F, Losurdo N, Teutonico A, Lomonte C. Effect of dialysate calcium concentrations on parathyroid hormone and calcium balance during a single dialysis session using bicarbonate hemodialysis: a crossover clinical trial. Am J Kidney Dis. 2012;59(1):92-101.

19. Urena P, Jacobson SH, Zitt E, Vervloet M, Malberti F, Ashman N, Leavey S, Rix M, Os I, Saha H, et al. Cinacalcet and achievement of the NKF/K-DOQI recommended target values for bone and mineral metabolism in real-world clinical practice--the ECHO observational study. Nephrol Dial Transplant. 2009;24(9):2852-9.

20. Friedl C, Zitt E. Role of etelcalcetide in the management of secondary hyperparathyroidism in hemodialysis patients: a review on current data and place in therapy. Drug Des Devel Ther. 2018;12:1589-98.

21. Pereira L, Meng C, Marques D, Frazao JM. Old and new calcimimetics for treatment of secondary hyperparathyroidism: impact on biochemical and relevant clinical outcomes. Clin Kidney J. 2018;11(1):80-8.

22. Rey E, Jacob CE, Koolian M, Morin F. Hypercalcemia in pregnancy - a multifaceted challenge: case reports and literature review. Clin Case Rep. 2016;4(10):1001-8.

23. Kidney Disease: Improving Global Outcomes CKDMBDUWG: KDIGO 2017 Clinical practice guideline update for the diagnosis, evaluation, prevention, and treatment of chronic kidney disease-mineral and bone disorder (CKDMBD). Kidney Int Suppl (2011) 2017, 7(1):1-59.

24. Dochez V, Ducarme G. Primary hyperparathyroidism during pregnancy. Arch Gynecol Obstet. 2015;291 (2):259-63.

25. Kamenicky P, Lecoq AL, Chanson P. Primary hyperparathyroidism in pregnancy. Ann Endocrinol (Paris). 2016;77(2):169-71.

26. Balzer MS, Gross MM, Lichtinghagen R, Haller H, Schmitt R. Got Milk? Breastfeeding and Milk analysis of a mother on chronic hemodialysis. PLoS One. 2015;10(11):e0143340.

\section{Publisher's Note}

Springer Nature remains neutral with regard to jurisdictional claims in published maps and institutional affiliations.

\section{Ready to submit your research? Choose BMC and benefit from:}

- fast, convenient online submission

- thorough peer review by experienced researchers in your field

- rapid publication on acceptance

- support for research data, including large and complex data types

- gold Open Access which fosters wider collaboration and increased citations

- maximum visibility for your research: over $100 \mathrm{M}$ website views per year

At BMC, research is always in progress.

Learn more biomedcentral.com/submissions 